Case Report

\title{
Refractory Biliary Catheter Leak Corrected by a Hybrid Closed Loop Catheter-Pump System
}

\author{
Ravi Murthy $\left(\mathbb{D},{ }^{1}\right.$ Varun Rachakonda $\mathbb{D}^{2},{ }^{2}$ and Juri Bassuner $\mathbb{D}^{3}$ \\ ${ }^{1}$ Departments of Interventional Radiology \& Investigational Cancer Therapeutics, M.D. Anderson Cancer Center, The University of \\ Texas at Houston, Houston, Texas 77030, USA \\ ${ }^{2}$ Houston Methodist Hospital, Department of Radiology, 6565 Fannin St., Houston, TX 77030, USA \\ ${ }^{3}$ Integrated IR/DR Residency, PGY-4, Saint Louis University School of Medicine, 3635 Vista Ave., St. Louis, MO 63110, USA
}

Correspondence should be addressed to Ravi Murthy; rmurthy@mdanderson.org

Received 12 November 2020; Revised 4 January 2021; Accepted 8 February 2021; Published 9 March 2021

Academic Editor: Atsushi Komemushi

Copyright (c) 2021 Ravi Murthy et al. This is an open access article distributed under the Creative Commons Attribution License, which permits unrestricted use, distribution, and reproduction in any medium, provided the original work is properly cited.

\begin{abstract}
The development of inoperable biliary obstruction in patients with liver, biliary, and pancreatic neoplasia is commonplace particularly in the advanced stages of these diseases. Under these circumstances, restoring bile flow to the gut is paramount in reestablishing homeostasis. Hitherto, this has been achieved by utilizing passive, gravity-dependent bilioenteric conduits with the use of perforated plastic catheters or metallic stents inserted either in a percutaneous transhepatic fashion or via endoscopic techniques. A frequent untoward event of biliary decompression utilizing percutaneous transhepatic catheters (PTC) is the development of pain, cholangitis, hyperbilirubinemia, or pericatheter bile leak due to the suboptimal normalization of bile flow. In some instances, the etiology of PTC malfunction can be correctly ascribed to catheter malposition and/or catheter lumen obstruction; however, in the majority, it remains radiographically occult on transcatheter cholangiography-the "gold standard." Regardless of findings, the management remains fluoroscopic repositioning or exchanges for larger diameter catheters to attempt to seal the pericatheter potential space and prevent bile seepage. Unfortunately, these maneuvers are met with limited and unpredictable levels of success. We present the successful management of an instance of recalcitrant external pericatheter bile leak mitigated by employing a hybrid closed loop biliary catheter-pump system by employing an assortment of FDA approved off-the-shelf medical devices.
\end{abstract}

\section{Case Presentation}

This study was conducted with Institutional Review Board approval and complied with the Health Insurance Portability and Accountability Act.

A 38-year-old female with an unresectable, locally advanced, intraductal papillary pancreatic mucinous neoplasm and an indwelling endoscopic metal stent for biliary obstruction developed bouts of cholangitis. The duodenal involvement from the pancreatic cancer rendered repeat intervention via the ERCP route difficult and therefore was not entertained, and the patient was referred for salvage percutaneous transhepatic biliary catheter decompression. Utilizing the combination of ultrasound-guided cholangiopuncture and fluoroscopic assistance, biliary access was achieved via the left lobe of the liver, and a 10-French Dawson-Mueller (Cook Medical, Bloomington, IN) Cope retention loop catheter was reformed within the common hepatic duct and connected to external gravity drainage. Copious pericatheter bile leak ensued. Transcatheter cholangiography failed to elucidate the etiology of the pericatheter leak. In accordance with our institutional clinical practice, the catheter was empirically "upsized" to 12,14 , and $16 \mathrm{Fr}$ diameter external (Mac-Loc, Cook Medical, Bloomington, IN) catheters in separate but closely spaced sessions without relief. The penultimate maneuver, which was expected to be unsuccessful $a$ priori, involved insertion of a $12 \mathrm{Fr}$ Ring internal-external biliary catheter (Cook Medical, Bloomington, IN) (Figure 1).

Conventional maneuvers had failed to remedy the profuse external pericatheter leaking. The underlying problem 


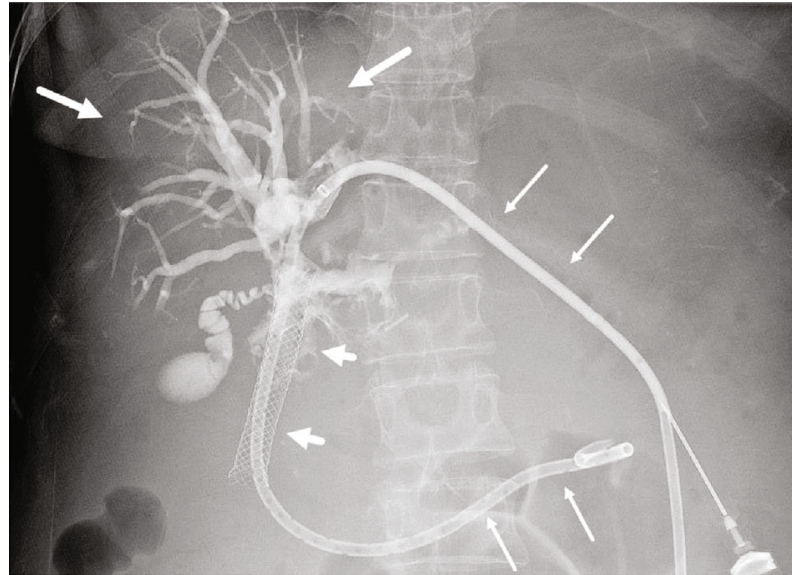

FIGURE 1: Contrast cholangiography via internal-external biliary drainage catheter (long arrows) demonstrates intrahepatic biliary ductal dilatation (large arrows). There is an occluded metal stent (arrowheads) with no flow of contrast beyond this point into the bowel.

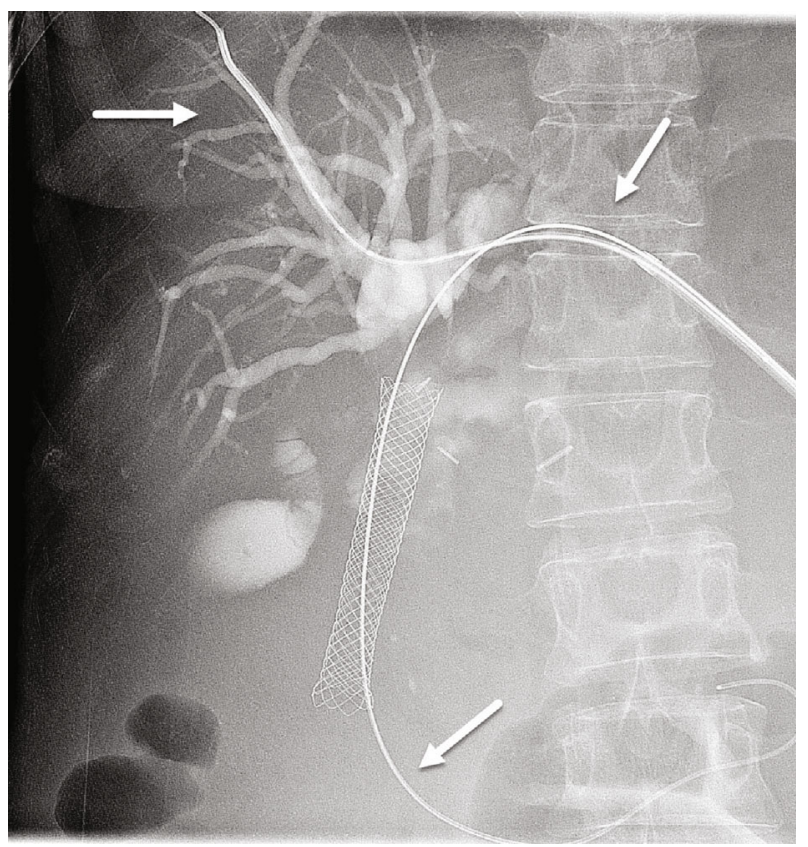

FIGURE 2: Exchange of internal external biliary drainage catheter for vascular sheath. Insertion of 2 guidewires, one each in the intrahepatic biliary radicles and one in the duodenum (long arrows).

was recognized as one of hydrodynamics. We therefore envisioned constructing a device that possessed an active propulsive mechanism for bile movement coupled with a dual lumen catheter system to facilitate bile movement separately from the intrahepatic bile ducts and gut as a possible remedy.

A 16-French, $32 \mathrm{~cm}$ Medcomp ${ }^{\circledR}$ Split Cath ${ }^{\circledR}$ dual lumen hemodialysis catheter (Medical Components, Inc., Harleysville, PA), which possesses the inherent ability to variably separate apart the catheter lumens, was identified as meeting requisite criteria. Following removal of the indwelling biliary catheter under fluoroscopy, two Super Stiff Amplatz wires

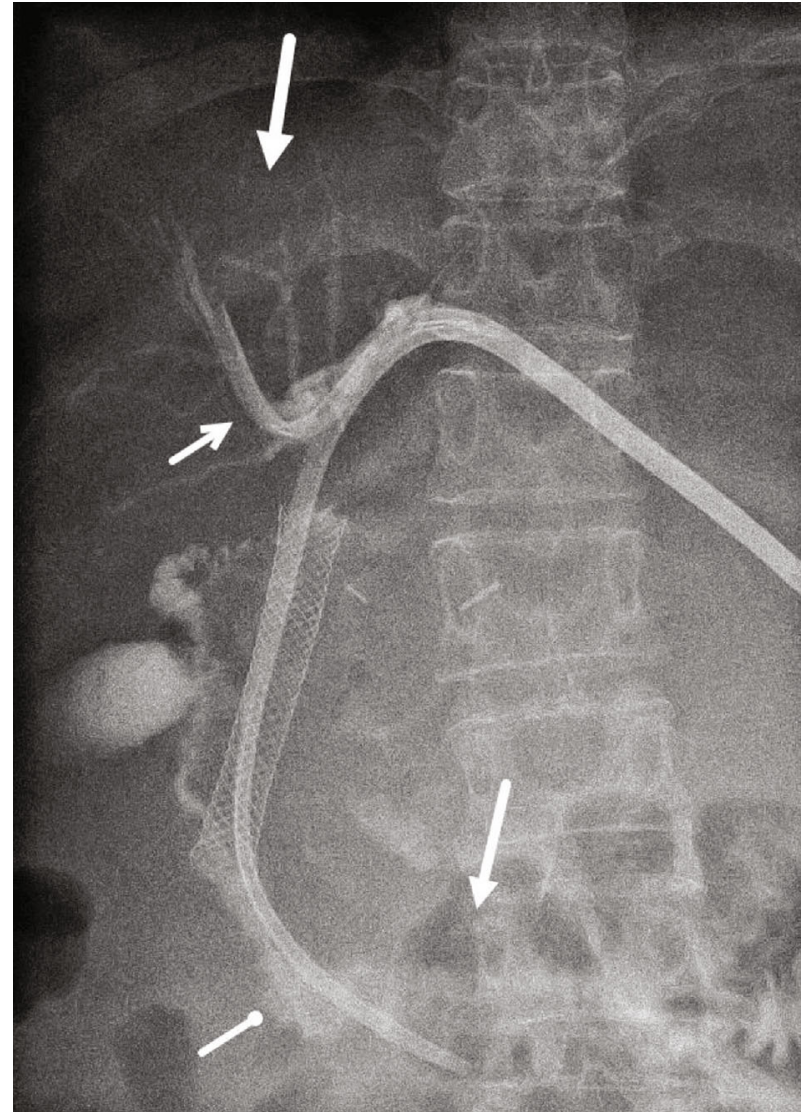

FIgURE 3: Contrast cholangiogram via dual, split lumen catheter. The efferent catheter limb drapes the biliary confluence (small arrow), and the afferent catheter limb is in the duodenal lumen (round tip arrow). Normal caliber of the intrahepatic radicles (large arrow) with contrast within the duodenum (long arrow) is noted indicating biliary decompression and bile deposited in the bowel.

(Boston Scientific, Natick, MA) were negotiated separately into the intrahepatic right lobe ducts and duodenum via an $8 \mathrm{Fr}$ vascular sheath. After measuring the intended length of the intrabiliary catheter component, one catheter moiety was manually trimmed and side holes were cut. The Dacron cuff was removed, and the catheter lumens were then simultaneously yet individually advanced over these two wires such that the efferent intrabiliary limb with additional side holes was draped over confluence of the right and left hepatic ducts, and the afferent enteric limb was advanced into the duodenum (Figure 2). The corresponding external limbs were connected to a Jackson-Pratt bulb (JP bulb) with luer lock extensions. As intended, the bulb was squeezed to create suction, and the stopper was closed to maintain the suction.

Radiographic confirmation of the functionality of the system was obtained by injecting contrast through the efferent, intrabiliary lumen and promptly connecting the primed JP bulb. Once aspirated bile (mixed with contrast) was visualized in the bulb, the bulb was squeezed, resulting in contrast being ejected through the efferent limb into the duodenum (Figure 3).

A table mock-up of the catheter was utilized to educate the primary caretaker who was instructed to decompress 


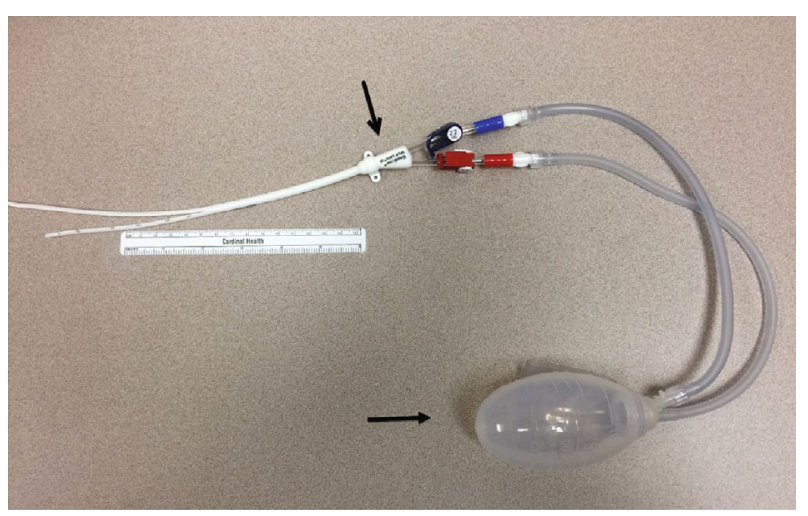

FIGURE 4: Hybrid closed loop catheter system; table mock-up. Dual channel, separable lumen hemodialysis catheter (open arrowhead) with additional side holes in the shorter venous limb connected to a JP bulb suction bulb (closed arrowhead).

the bulb when it filled (Figure 4). The patients' leaking decreased dramatically, and she was discharged home following at-best palliation of her other medical issues until her demise 2 months later.

\section{Discussion}

Herein, we describe an application of existing off-label device technologies to mitigate persistent pericatheter bile leak with the added benefit of allowing replenishment of bile to the gut. This rudimentary hybrid closed loop catheter-pump system allowed palliation of her bile leaking and hospital discharge.

In clinical practice, the underlying principles of the PTC technique and equipment have remained unchanged over 5 decades since the initial descriptions of percutaneous biliary catheter drainage [1-4]. Technical success remains high, but adverse events such as bile loss, leaking, and cholangitis have remained a major source of morbidity [5-7]. Bile flows within the PTC along small pressure gradients [8]. Dehydration and bile contact with enteric content further alters bile viscosity [9]. Several investigators have attempted to augment the transfer of bile to the gut by increasing the catheter diameter [10], external biliary catheter crosslinking to an internal biliary catheter [11], or a jejunostomy via a peritoneovenous shunt pump [12], anchoring with a balloon tip catheter to prevent migration [13], and creation of additional side holes [14] with variable and unreliable levels of efficacy.

Hepatobiliarypancreatic cancers are in an exclusive group of cancers whose incidence is increasing, and mortality is unchanged. $[15,16]$ Their lethality is largely due to the consequences of biliary obstruction. Furthermore, as therapeutic and supportive cancer control measures improve survival, the expected increasing prevalence of hepatic metastases will also result in higher numbers of patients with biliary obstruction and the need for biliary decompression. This implies a need for evaluating for improvements in PTC-related technologies, as our approach has shown, that may assist in providing the required support for the expected increase in demand for these and allied services.

\section{Data Availability}

Data is available within the secure institutional electronic medical record in which the corresponding author is faculty.

\section{Conflicts of Interest}

The authors declare that there is no conflict of interest regarding the publication of this article.

\section{References}

[1] T. Ukai, S. Oshima, H. Kuriyama, R. Aso, and J. Okamura, "A new device for external biliary drainage using percutaneous transhepatic cholangiography," Medical journal of Osaka University, vol. 22, no. 1, pp. 85-95, 1971.

[2] W. Molnar and A. E. Stockum, "Relief of obstructive jaundice through percutaneous transhepatic catheter-a new therapeutic method," The American Journal of Roentgenology, Radium Therapy, and Nuclear Medicine, vol. 122, no. 2, pp. 356-367, 1974.

[3] F. Burcharth and N. Nielbo, "Percutaneous transhepatic cholangiography with selective catheterization of the common bile duct," AJR American journal of roentgenology, vol. 127, no. 3, pp. 409-412, 1976.

[4] E. J. Ring, J. W. Husted, J. A. Oleaga, and D. B. Freiman, “A multihole catheter for maintaining longterm percutaneous antegrade biliary drainage," Radiology, vol. 132, no. 3, pp. 752-754, 1979.

[5] P. R. Mueller, E. van Sonnenberg, and J. T. Ferrucci Jr., "Percutaneous biliary drainage: technical and catheter-related problems in 200 procedures," AJR American journal of roentgenology, vol. 138, no. 1, pp. 17-23, 1982.

[6] S. Kamiya, M. Nagino, H. Kanazawa et al., "The value of bile replacement during external biliary drainage: an analysis of intestinal permeability, integrity, and microflora," Annals of surgery, vol. 239, no. 4, pp. 510-517, 2004.

[7] R. O. B. Murthy, S. Huang, A. Mahvash et al., Advanced hepato-pacreatico-biliary cancer related malignant biliary obstruction: percutaneous transhepatic catheter biliary diversion 2013-2015 MD Anderson Cancer Center Experience, 2016.

[8] E. vanSonnenberg, J. T. Ferrucci Jr., C. C. Neff, P. R. Mueller, J. F. Simeone, and J. Wittenberg, "Biliary pressure: manometric and perfusion studies at percutaneous transhepatic cholangiography and percutaneous biliary drainage," Radiology, vol. 148, no. 1, pp. 41-50, 1983.

[9] R. K. Kerlan Jr., G. Stimac, A. C. Pogany, and E. J. Ring, "Bile flow through drainage catheters: an in vitro study," AJR American journal of roentgenology, vol. 143, no. 5, pp. 1085-1087, 1984.

[10] S. H. Lee, E. V. Sonnenberg, H. B. D'Agostino, and L. Tanenbaum, "Laboratory analysis of catheters for percutaneous abscess drainage," Minimally Invasive Therapy, vol. 3, no. 4, pp. 233-237, 2009.

[11] C. D. Becker, J. S. Fache, R. G. Gibney, and H. J. Burhenne, "External-internal cross-connection for bilateral percutaneous biliary drainage," AJR American journal of roentgenology, vol. 149, no. 1, pp. 91-92, 1987.

[12] K. Araki, M. Kure, M. Kobayasi, M. Sugito, and T. Ogata, "A new method for palliation of malignant obstructive jaundice utilizing a peritoneo-venous shunt pump," Hepato-Gastroenterology, vol. 41, no. 1, pp. 38-40, 1994. 
[13] S. Karstrup, T. Mygind, and V. Hennild, "Percutaneous transhepatic external biliary drainage utilizing a pig tail balloon catheter," Acta radiologica, vol. 35, no. 5, pp. 509-511, 1994.

[14] A. Y. Li, D. H. Ballard, and H. B. D'Agostino, "Biliary drainage catheters fluid dynamics: in vitro flow rates and patterns," Diagnostic and Interventional Imaging, vol. 98, no. 4, pp. 355-358, 2017.

[15] A. Jemal, E. P. Simard, J. Xu, J. Ma, and R. N. Anderson, "Selected cancers with increasing mortality rates by educational attainment in 26 states in the United States, 19932007," Cancer Causes \& Control, vol. 24, no. 3, pp. 559-565, 2013.

[16] L. Rahib, B. D. Smith, R. Aizenberg, A. B. Rosenzweig, J. M. Fleshman, and L. M. Matrisian, "Projecting cancer incidence and deaths to 2030: the unexpected burden of thyroid, liver, and pancreas cancers in the United States," Cancer Research, vol. 74, no. 11, pp. 2913-2921, 2014. 